\title{
DESIGN AND CFD ANALYSIS OF CEILING FAN FOR REGULAR ROOM SIZE
}

\author{
Pushpesh Singh \\ ME Student, Department of Mechanical Engineering, \\ Pillais HOC College of Engineering and Technology, \\ University of Mumbai, Maharashtra, India

\section{Dr. Gajendra Vasantrao Patil} \\ Professor, Department of Mechanical Engineering \\ Pillais HOC College of Engineering and Technology, \\ University of Mumbai, Maharashtra, India
}

\begin{abstract}
Fans are playing a major role around the globe for effective and pocket friendly cooling, especially in the region of Asia where humidity is high. Thermal comfort being one of the most important factors for improvement in working environment for better quality of work. Moving of air around the body helps sweat evaporation and makes body feel comfortable. Mixing of air from top to bottom of the area so as to neutralize the change in temperature is done by fans effectively than any other means. Destratification of air is the biggest problem faced in any enclosed area which can be rectified by using fans. CFD Analysis is performed on the designed ceiling fan to analyze the airflow around the area of interest.
\end{abstract}

Keywords: CFD, Destratification, Ceiling fan, Solid works and Analysis.

Cite this Article: Pushpesh Singh and Dr. Gajendra Vasantrao Patil, Design and CFD Analysis of Ceiling Fan for Regular Room Size. International Journal of Mechanical Engineering and Technology. 11(4), 2020, pp. 25-33. https://iaeme.com/Home/issue/IJMET?Volume $=11 \&$ Issue $=4$

\section{INTRODUCTION}

This study examines the airflow in a room due to ceiling fan [1] [2].Ceiling fans have been used since decades to improve indoor thermal comfort in specified area. However, recent years have witnessed a significant increase in the use of air conditioning as a means to achieve comfort, and therefore in the total energy consumption and related $\mathrm{CO} 2$ emissions [3]. Ceiling fans are still viable options to limit use of air conditioners or in combination with air conditioners without compromising on thermal comfort and still achieving energy savings. Ceiling fans generate non-uniform velocity profiles, and therefore relatively non-uniform thermal environments, whose characteristics may be tough to analyse with simple modelling methods [3]. 
In case of developing economy and rising level of populace which can bear the cost of procurement and operation of air-conditioning system for higher need of Thermal comfort, India has encountered ascend in sales of ventilation systems [4]. It is the most cost-effective methods to circulate area in a desired space [5]. Ceiling fans are large, lightweight, propeller fan wheels which are suspended from the ceiling and blowing a gentle breeze down the floor [5].

Energy constraints encourage the use of energy-effective electrical appliances such as ceiling fans to achieve indoor thermal comfort, especially in developing countries (e.g. India) and regions with mild and warm climates. Ceiling fans accounted for approximately $6 \%$ of residential electricity consumption in India in 2000, which might increase to $9 \%$ in 2020 [6].

The air velocities are low due to small blade angles and low speeds. Ceiling fan mainly consist of a HUB, BLADES, CONNECTORS and MOTOR. Ceiling fans basically works on the principle of DESTRATIFICATION, where hot air the at the ceiling is pushed down to mix with cold air at the bottom so that the overall temperature of the room can be equalized. The maximum air velocity, just below the fan is $600 \mathrm{fpm}$ and at floor level is $100 \mathrm{fpm}$. There is a vast potential for energy conservation and improved comfort by developing optimized fan design.

\section{DESIGN}

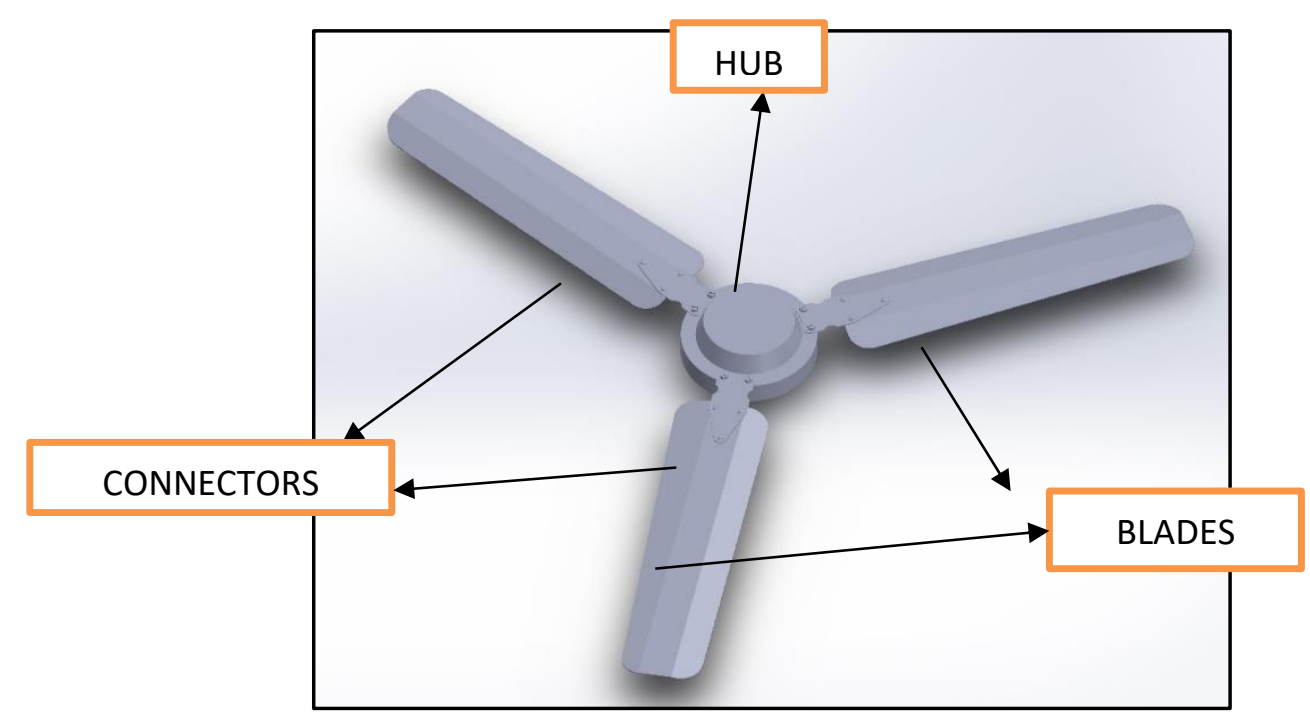

Figure 1 Ceiling fan design in solidworks

\subsection{Blade Design}

Ceiling fan blades are basically single thickness sheet metal profiles rather being a full airfoil profile. material used for blade design is aluminium as it is light weight and strong. Selection of single sheet profile reduces the making cost as well as the operating cost by overall reducing the weight of the ceiling fan. 


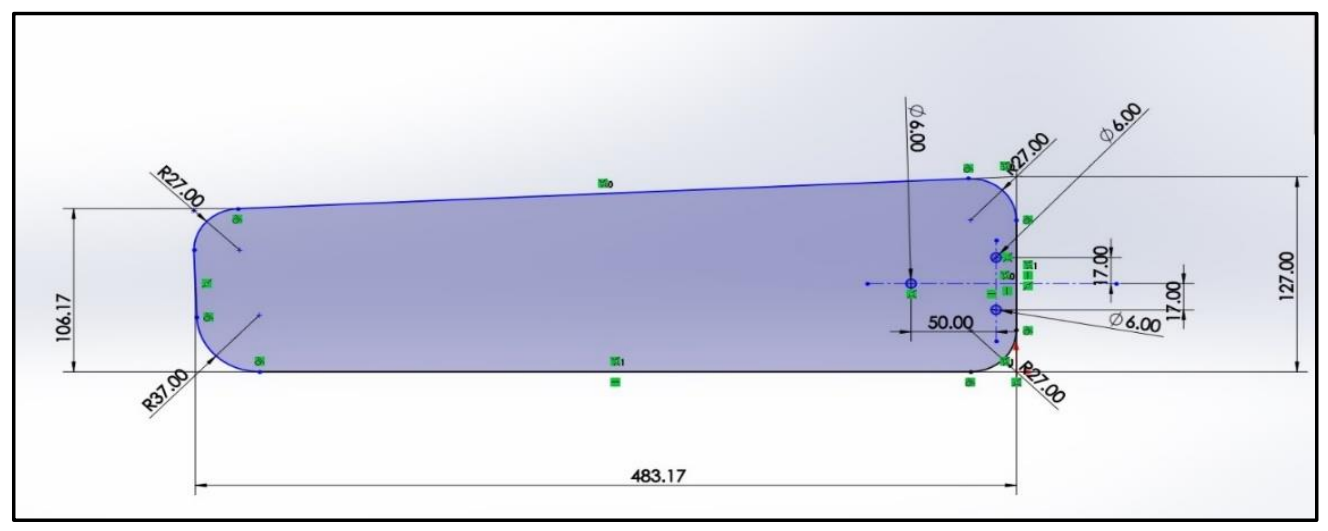

Figure 2 Ceiling Fan Blade Design

FAN BLADE WIDTH: The fan blade is wider at the hub side and smaller at the tip side it is generally because the lower velocity at the hub side is more which leads the tip side to circulate more air if symmetrical. For an optimum flow the width of the fan blade should be more at hub side. Fan width depends on the amount of airflow required by fan, typically the width of ceiling fan ranges from 100-200 mm. More the width more lift more motor horsepower required for optimum design consideration maximum width of $127 \mathrm{~mm}$ is taken for design.

FAN BLADE LENGTH: The length of the blade is taken with respect to the amount of CFM required and the area under which the fan is placed. Typically, the 200-400 square feet area requires fan blade length of $400 \mathrm{~mm}$ to $600 \mathrm{~mm}$ to provide CFM of 2000 to 8000 . But for optimum design we will consider the fan length of $483.17 \mathrm{~mm}$, as if the length of fan is increased more, more motor power is required and thus more operating cost.

\section{Fan Blade Profile}

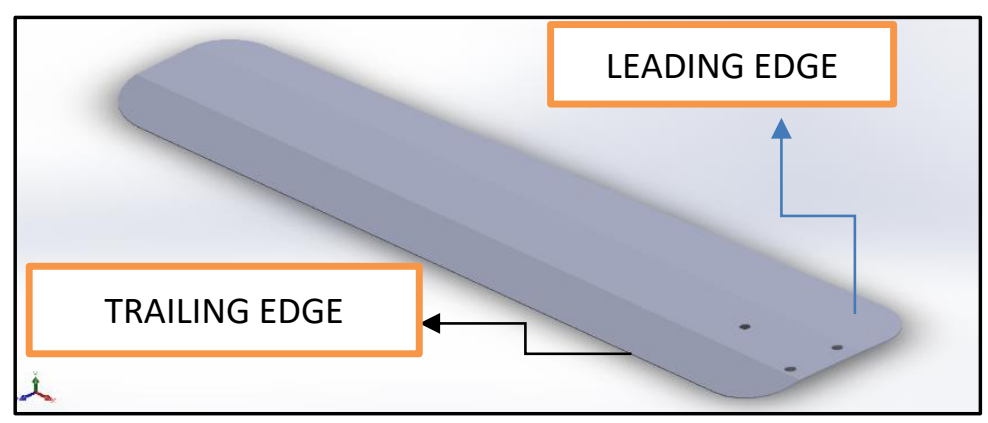

Figure 3 Ceiling Fan Blade

The fan blade profile is a single thickness sheet metal profile with leading and trailing edges. The leading edge first encounters air and the blade angle of leading edge varies from $2^{\circ}$ to $5^{\circ}$ and the trailing edge varies from $8^{\circ}$ to $10^{\circ}$ for optimum airflow and producing a uniform horizontal jet of air column. The pitch of blade should be constant all over the region of blade to get more air flow per revolution. The trailing edge angle wider is higher as the maximum thrust is produced in that region.

\subsection{Hub Design}

Hub is the center part of the fan where blades are connected, and motor is housed. Material used to design hub is carbon steel. The Hub diameter is small about 15 percent of the wheel diameter and this is adequate as the ceiling fans operates at or near to free delivery. Hub design is important as the size and shape of hub effects the circulation of air. It is design in 
such a way that it should not allow the recirculation of air in the hub area due to higher static pressure. It is the heaviest part of fan so the design should be optimum as smaller hub size will result in reverse flow of air and larger hub size will result in increase in velocity pressure at the tip side of ceiling fan. The optimum hum design reduces the stalling effect.

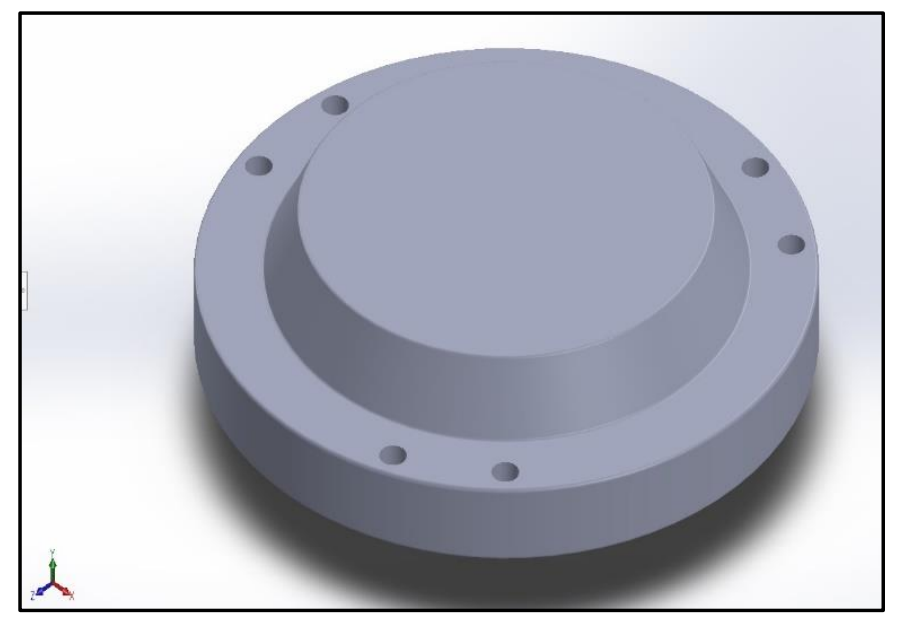

Figure 4 Ceiling Fan Hub (Spider) Top View

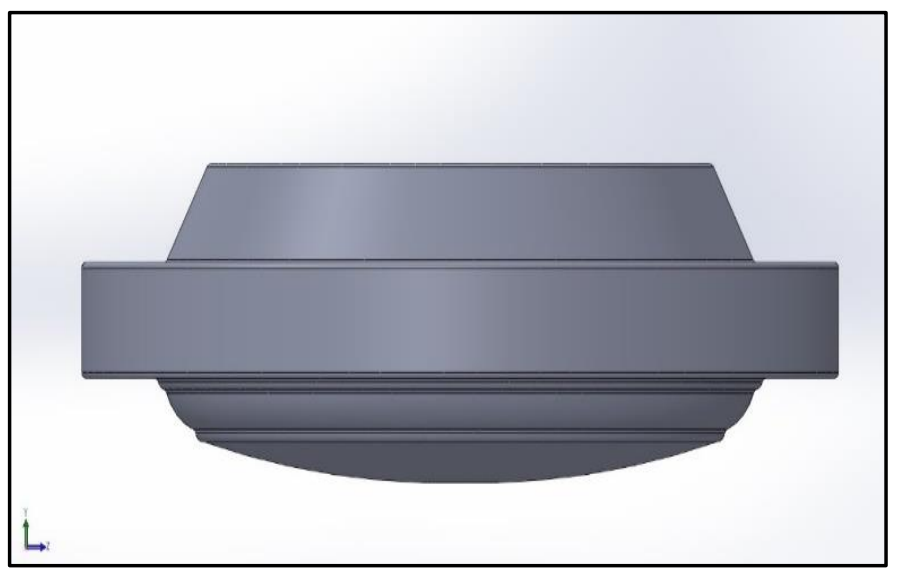

Figure 5 Ceiling Fan Hub Side View

Ceiling fan uses single phase induction motor, low speed motors. These are inside out motors with inside stationary and outside rotating. These motors usually have 16 to 22 poles of windings with a capacitor. These motors ranges from 270 to $400 \mathrm{rpm}$. The motor typically consumes $60 \mathrm{w}$ to $200 \mathrm{w}$ of power.

\section{CEILING FAN ANALYSIS}

Ceiling fans have been used since decades as a mean to improve indoor thermal comfort. The fans produce an inexpensive way to cool the surrounding. After designing the fan, it is time to perform analysis on it. Analysis can be done in following phases:

- Site description

- Modelling

- Meshing

- Simulation

- Validation

The above criteria will determine the airflow and efficiency of the fan in a room. 


\subsection{Site Description}

The site which has been chosen is a room of a building with 3 doors and one window. From analysis point of view the doors and windows are kept close so that there is no escape or addition of external air in the room. The ceiling fan is placed at center of the room. Area of room is $31.24 \mathrm{~m}^{3}$.

\subsection{Modelling in Solidworks}

A 3D model has been created using solidworks 2018 with a following room size and fan size

Length of room: $3.6 \mathrm{~m}$

Width of room: $3.1 \mathrm{~m}$

Height of room: $2.8 \mathrm{~m}$

Area of room: $31.24 \mathrm{~m}^{3}$

Fan cylinder diameter: $1.2 \mathrm{~m}$

Fan cylinder height: $0.3 \mathrm{~m}$

Volume of fan cylinder: $0.35 \mathrm{~m}^{3}$

Room is considered to be a closed volume without any inlet and outlet. The roof fan is solely considered to a momentum source.

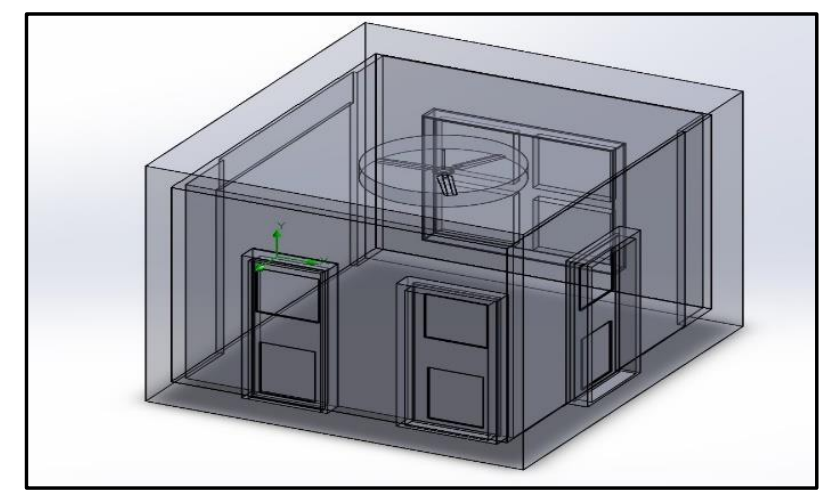

Figure 6 Ceiling fan in a room

For the analysis point of view the inner fluid domain will be considered as the flow of air will be in the inner side of the room. The fan will be considered as a cylinder with $1200 \mathrm{~mm}$ of diameter and $200 \mathrm{~mm}$ of height. As putting the actual fan for calculation will involve high computing power.

The rotational zone involved 1.12 percent of the recreation field.

\subsection{Meshing}

In this study the Ansys is used for meshing. Structured Tetrahedron meshing technique is used by keeping skewness at 0.9. the room and the fan and divided in number of cells or finite volumes. The mesh independence test conducted on the model reveals that the solution of problem is independent of the mesh size.

The meshing is fine near the fan zone. The room is meshed with element size of $160 \mathrm{~mm}$ and fan with $1 \mathrm{~mm}$. 


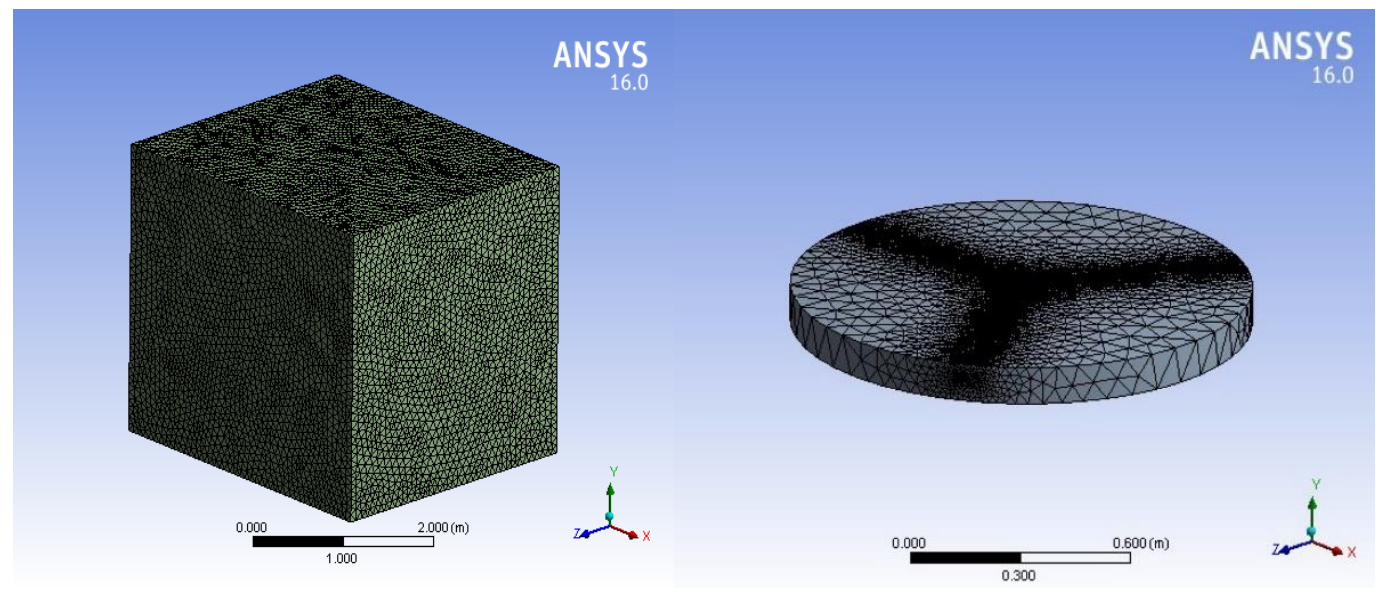

Figure 7 Room and Fan Enclosure Mesh

\subsection{Simulation}

After meshing the geometry is transferred to CFD simulation software where the initial conditions of fan are defined with frame motion. The pressure-based solver with gravity is used. The cell zone condition defined were fan as 3D fan zone and the room as walls.

Transient model with turbulent flow helps in finding the turbulent streamline flowing around the room. The fan is rotating at a speed of $370 \mathrm{rpm}$.

The SST k- $\omega$ turbulence model delivers the most practical results. Since there are no inlet and outlet in this simulation, the conservation target does not have any affect.

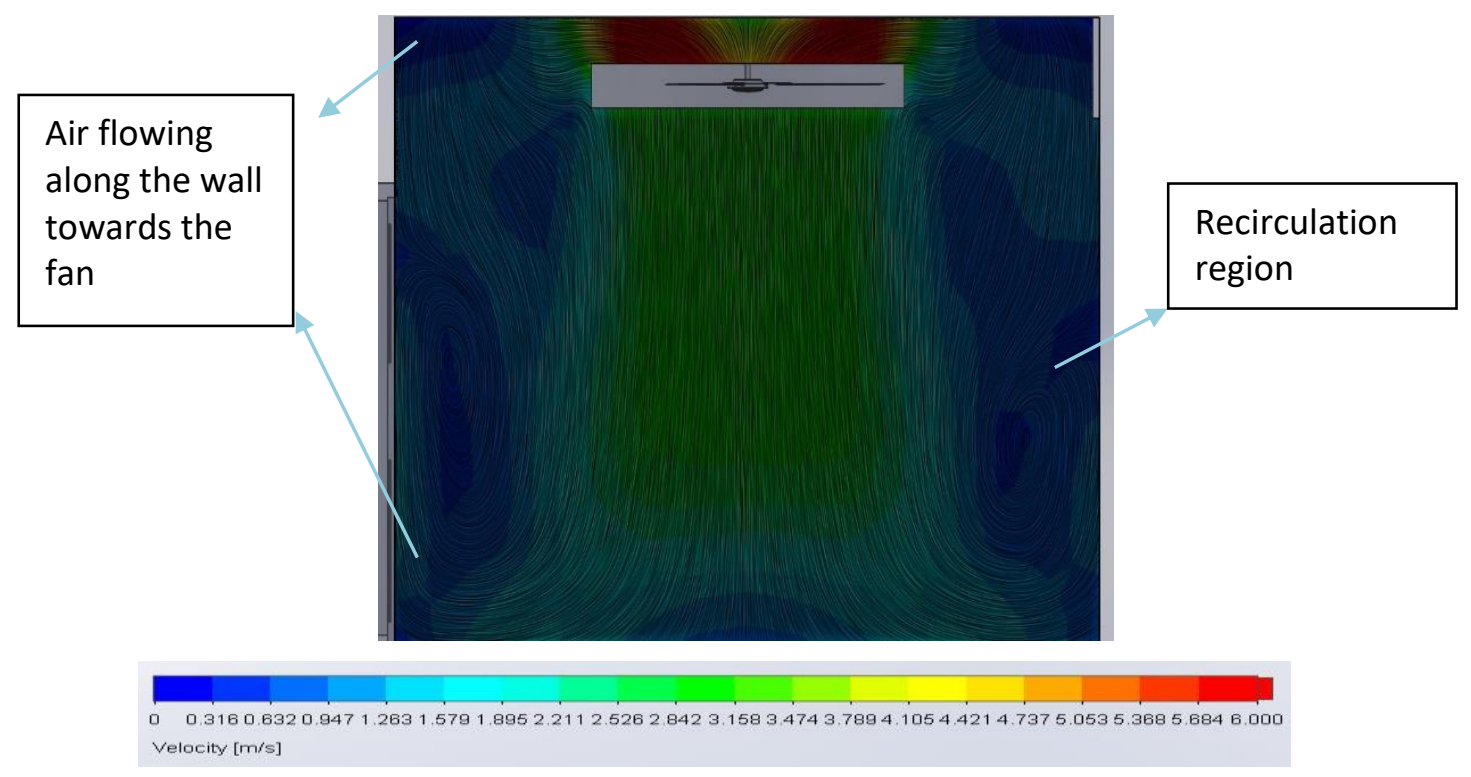

Figure 8 Velocity Streamlines around the room

From the above figure it can be noted that the velocity below the fan is ranging from 2.5-3 $\mathrm{m} / \mathrm{s}$. The velocity is moving from red zone with highest velocity to the blue zone with comparatively low velocity. The region below the fan and the region near the wall are getting maximum flow of air.

The region between the fan and wall are less air as the air column produced by the ceiling fan is of lesser diameter which starts from the fan reaches the floor and then a horizontal jet is formed which moves till the walls. 
The circulation starts from fan and end at the fan. The velocity above the fan is high due to high suction pressure produced by the rotation of the fan.

Below are results of airflow in a room at measured at different height, so that the flow around various region in a room can be determined.

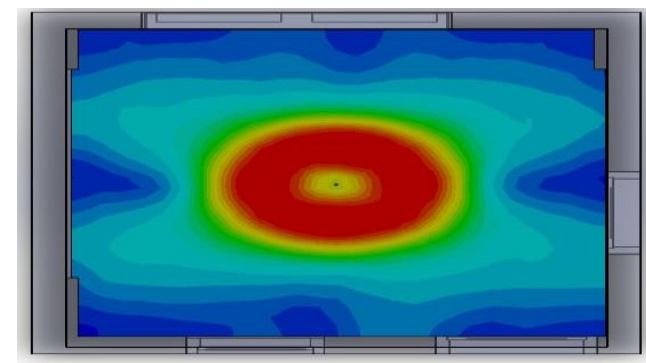

(a) $300 \mathrm{~mm}$ above the fan

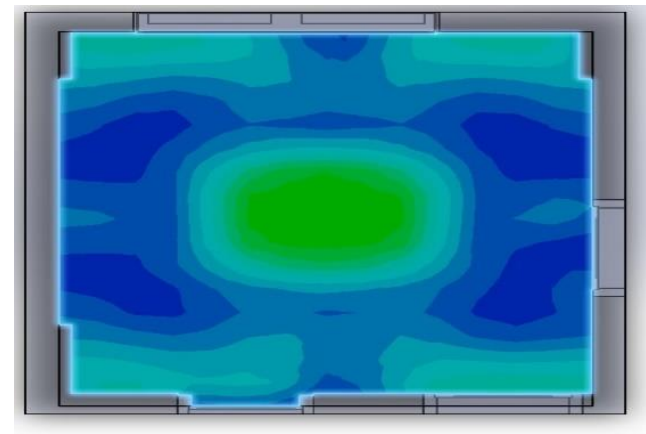

(b) $500 \mathrm{~mm}$ below the fan

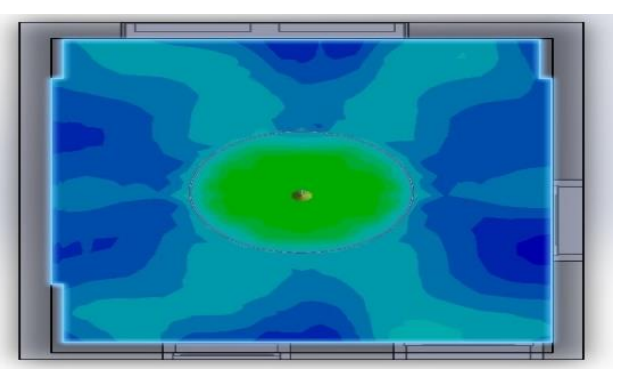

(d) $100 \mathrm{~mm}$ below the fan

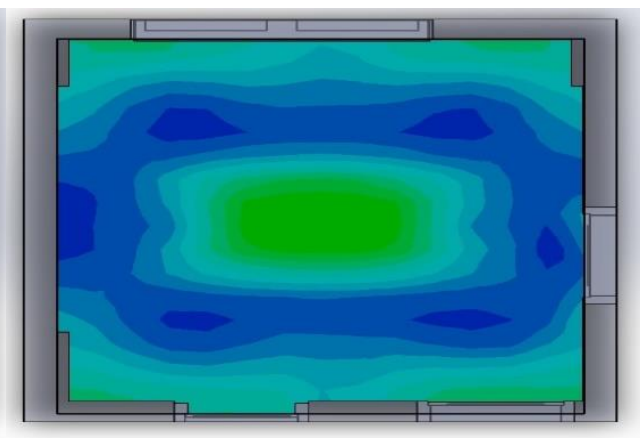

(e) $1000 \mathrm{~mm}$ below the fan

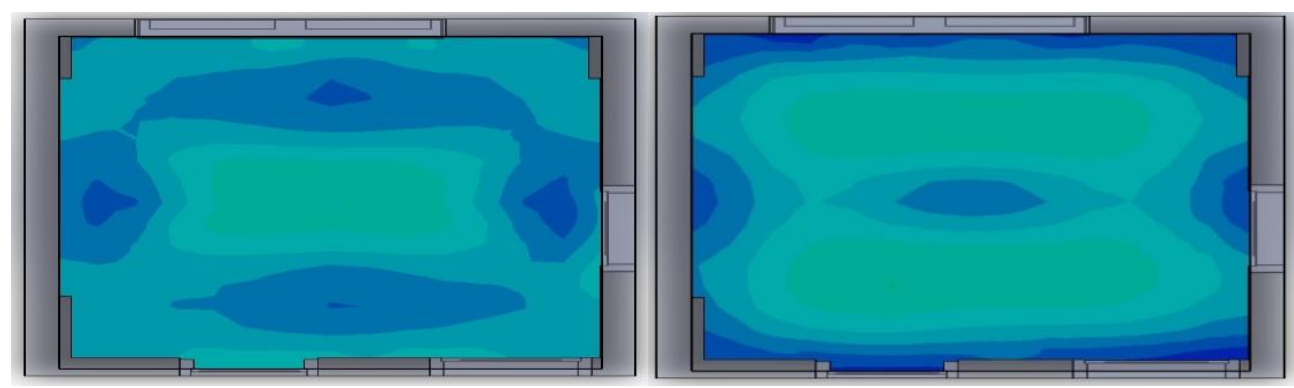

(c) $2000 \mathrm{~mm}$ below the fan

(f) bottom of the floor

Figure 9 Airflow at different level of room from ceiling fan

From figure 9 it can be studied that how air flows in the room, velocity below the fan and near the walls is more than rest of the space. There is thermally stratified zone just few centimeters away from the fan zone.

\subsection{Validation}

It is a process in which the simulated results are compared with experimental results. For validation we have considered an anemometer (UA-965), the room considered for simulation is of same dimensions which was designed in solidworks. For proper experimental results the doors and windows are closed so there is no inlet and outlet of air from the computational zone. The comparison between both the measured and simulated values is shown below 
Pushpesh Singh and Dr. Gajendra Vasantrao Patil

Table 1 Validation of Simulated values

\begin{tabular}{|l|c|c|c|}
\hline \multicolumn{1}{|c|}{ Distance from the fan } & Simulated value & Measured value & \% error \\
\hline $300 \mathrm{~mm}$ above the fan & $5.3 \mathrm{~m} / \mathrm{s}$ & $4.3 \mathrm{~m} / \mathrm{s}$ & 18 \\
\hline $100 \mathrm{~mm}$ below the fan & $3.8 \mathrm{~m} / \mathrm{s}$ & $3.6 \mathrm{~m} / \mathrm{s}$ & 8 \\
\hline $500 \mathrm{~mm}$ below the fan & $3.4 \mathrm{~m} / \mathrm{s}$ & $3 \mathrm{~m} / \mathrm{s}$ & 11 \\
\hline $1000 \mathrm{~mm}$ below the fan & $2.7 \mathrm{~m} / \mathrm{s}$ & $3 \mathrm{~m} / \mathrm{s}$ & 10 \\
\hline $2000 \mathrm{~mm}$ below the fan & $1.5 \mathrm{~m} / \mathrm{s}$ & $2.4 \mathrm{~m} / \mathrm{s}$ & 17 \\
\hline Floor $\mathrm{mm}$ below the fan & $1.5 \mathrm{~m} / \mathrm{s}$ & $2 \mathrm{~m} / \mathrm{s}$ & 25 \\
\hline
\end{tabular}

The above distances for measurement are taken as at floor the velocity of air at feet can be calculated, at $2000 \mathrm{~mm}$ below fan airflow around knees while sitting can be studied, at $1000 \mathrm{~mm}$ airflow around the face while sitting and at $500 \mathrm{~mm}$ below the fan the airflow around the face while standing. From the above results it can be seen that the airflow above the fan and airflow at floor has large difference in the velocity as above the fan due to recirculation of air the difference can arise and at floor due to friction.

\section{RESULTS}

From the CFD analysis in a room the velocity streamlines observed are depleting from the source towards the floor. From figure 9 (a) and 9 (d) it can be observed that the velocity is in the range of $3 \mathrm{~m} / \mathrm{s}$ and above when originating from the source of momentum and eventually the magnitude of velocity decreases with increasing distance from the fan towards the floor.

From figure 9 (e), if a human is standing under the fan the airflow of around $2 \mathrm{~m} / \mathrm{s}$ can be observed over his body which can increases the thermal comfort in a room.

Form figure 9 (c) and 9 (f) if a person is sitting on a chair or sleeping on a bed below the fan, the air breeze of $1.5 \mathrm{~m} / \mathrm{s}$ to $1.8 \mathrm{~m} / \mathrm{s}$ can be felt which is adequate for a human comfort.

Along the walls air velocity is around $1 \mathrm{~m} / \mathrm{s}$ to $1.3 \mathrm{~m} / \mathrm{s}$. In the recirculation zone which is between the fan zone and the wall the air velocity is less than $1 \mathrm{~m} / \mathrm{s}$ which is less as per the thermal comfort of human being.

The recirculation zones can be optimized by increasing the blade angle of ceiling fan which in result will increase the fan zone covered under the fan and hence increasing the air velocity in recirculation zone which results in better air quantity from the fan.

\section{FUTURE SCOPE}

1. The efficiency of fan can be studied by changing the blade angles for the specified area of interest.

2. Airfoil can be used for better Drag coefficient which results in smooth airflow along the foil with increase in air output from the fan.

3. Redesigning the HUB to remove the recirculating area around the Fan which can increase the efficiency of the fan.

4. Redesigning the blades so that the work done by the blades is even along the blade length which increase the airflow.

5. Redesigning the room for smooth surfaces along the corner which results in more air back to the fan.

\section{CONCLUSION}

From the CFD results it can be concluded that the larger air columns can be observed near the fan and along the floor and side walls. As the Movement of air depicts that the objects from 
the corners should be kept at a distance from the wall so that the amount of air flowing back to fan can be increased and thus resulting more airflow from the fan towards the floor.

\section{REFERENCES}

[1] S.V.S.A.Y. Anand, "Transient 3-D Modelling of ceiling fan for achieving Thermal Comfort," Building Performance Analysis Conference, 2018.

[2] N.S.K. Ramadan Bassiouny, "Studying the features of air flow induced by a room ceilingfan," Energy and Buildings, 2011.

[3] C.M.L.D.R.R.S.Y. Babich F, "Transient three dimensional CFD modelling of ceiling fans," Building and Environment, 2017.

[4] R.R.U.S.C.M.S.S.K. Ankur Jain, "Experimental Investigation of the Flow Field of a Ceiling Fan," 2004.

[5] A.L.S.S.E.A. Shuo Liua, "Detailed experimental investigation of air speed field induced by ceiling fans," Building and Environment, 2018.

[6] J.D. Anderson, in computational fluid dynamics, MCGRAW-HILL, 2012.

[7] F.P. Bleier, Fan Handbook.

[8] K.S.Y. Yoshihisa Momoi, "Modeling of Ceiling Fan Based on Velocity Measurement for CFD Simulation of," Journal of Environmental Engineering, 2004.

[9] S.L.Y.G.H.Z.E.A.L.Z.J.L. Wenhua Chenb, "Experimental and numerical investigations of indoor air movement," Building and Environment, elsevier, 2018.

[10] H. Versteeg, "AN introduction to CFD".

[11] M.A.A.A.H. Tauseef Tauqeera, "Realization for low cost and energy efficient ceiling fans in the developing," Renewable and Sustainable Energy Reviews, 2017.

[12] L.R.M.M.R. Son H. Ho, "Thermal comfort enhancement by using a ceiling fan," Applied Thermal Engineering, elsevier, 2009.

[13] D.C.P. a. D.P. Mishra, "CFD Simulations for the Selection of an Appropriate Blade Profile for Improving Energy Efficiency In Axial Flow Mine Ventilation Fans," Journal of Sustainable Mining, 2014. 